\title{
Manufacturing aspects of active acoustic lining panel
}

\section{EMUS 2019}

\author{
KAI GONET ${ }^{*}$, STEFAN STEEGER ${ }^{*}$, STEPHAN ALGERMISSEN ${ }^{\dagger}$, \\ VICTOR LUNGAHO ${ }^{\dagger \dagger}$ \\ *INVENT GmbH \\ 38112 Braunschweig, Germany \\ e-mail: kai.gonet@invent-gmbh.de, web page: http://www.invent-gmbh.de \\ ${ }^{\dagger}$ Deutsches Zentrum für Luft- und Raumfahrt \\ 38108 Braunschweig \\ e-mail: stephan.algermissen@dlr.de,web page: http://www.dlr.de \\ ${ }^{\dagger}$ Trackwise \\ Gloucestershire GL20 8NB \\ United Kingdom \\ e-mail: victor.lungaho@trackwise.co.uk -web page: www.trackwise.co.uk
}

Key words: Interior Design, Aviation Engineering, Noise Reduction

\begin{abstract}
This paper shows the technical aspects and the progress of manufacturing a lining concept with actuators and sensors for noise reduction within the cabin of aircraft with CROR engine. The structural integration, the repair possibilities and the serial production of such a lining are focused.
\end{abstract}

\section{INTRODUCTION}

One of the possibilities of reducing exhaust gases and fuel consumption are new propulsion concepts in the transport sector. Even in aviation it does not stop for engineering efforts to break new ground. Unfortunately, some of the new concepts offer the desired improvement, but with unwanted side effects for pilots and/or passengers.

One of these examples for a new fuel saving concept are counter rotating open rotors (CROR). This engine concept has one negative side effect. The engines with the two propellers generate unpleasant vibrations and noise for passengers in a frequency band of $500 \mathrm{~Hz}$. These vibrations are transmitted by the complex vortex of the propellers from the engine nacelles through the structure right into the cabin, affecting the passengers.

Within the EU project ACASIAS an active structural acoustic control system (ASAC) is being integrated within a lining of an aircraft. The task of the active fairing structure is to detect the vibrations and to eliminate these with oscillations.

Some of the mayor issues like structural integration, repair and maintenance is being presented in this paper. 
Kai Gonet, Stefan Steeger, Stephan Algermissen, Victor Lungaho

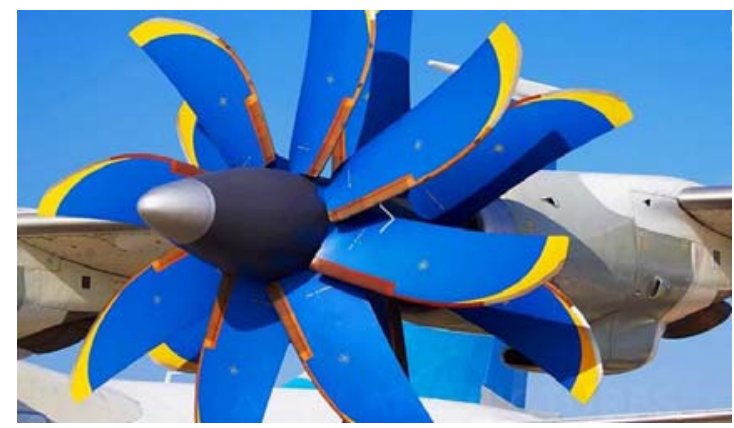

Figure 1: Closer look to an engine with counter-rotating propellers. Aircraft AN-70 (taken from internet picture research [2])

\section{CURRENT PRODUCTION PROCESS}

In order to realize this concept of a new lining and to be able to manufacture it for test purposes according to a real environment, it is necessary to analyze an inventory of the current production methods of these parts. State of the art for production such a lining is realized with presses.

In the manufacturing process, a layer of phenolic resin impregnated glass fabric (GFRP) is pressed onto a paper honeycomb. The prepreg, which will later be inside the aircraft, is very finely meshed and is painted in a separate working process according to customers order. The outer fabric layer is very roughly woven fabric and remains untreated. The two fabric layers

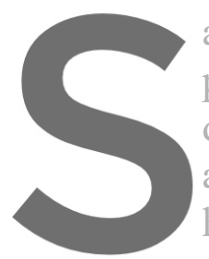
are pressed at high temperature (approx. $170^{\circ} \mathrm{C}$ ) and high pressure (approx. 12bar) paper honeycomb to fo distance, the honeycam areas where greater strength is required (e.g. honeycomb in combination with the GFRP entire hardening process is called HIHO (hot in, hot out).

Register for free at https/howw.scipedia.com to download the version without the watermark

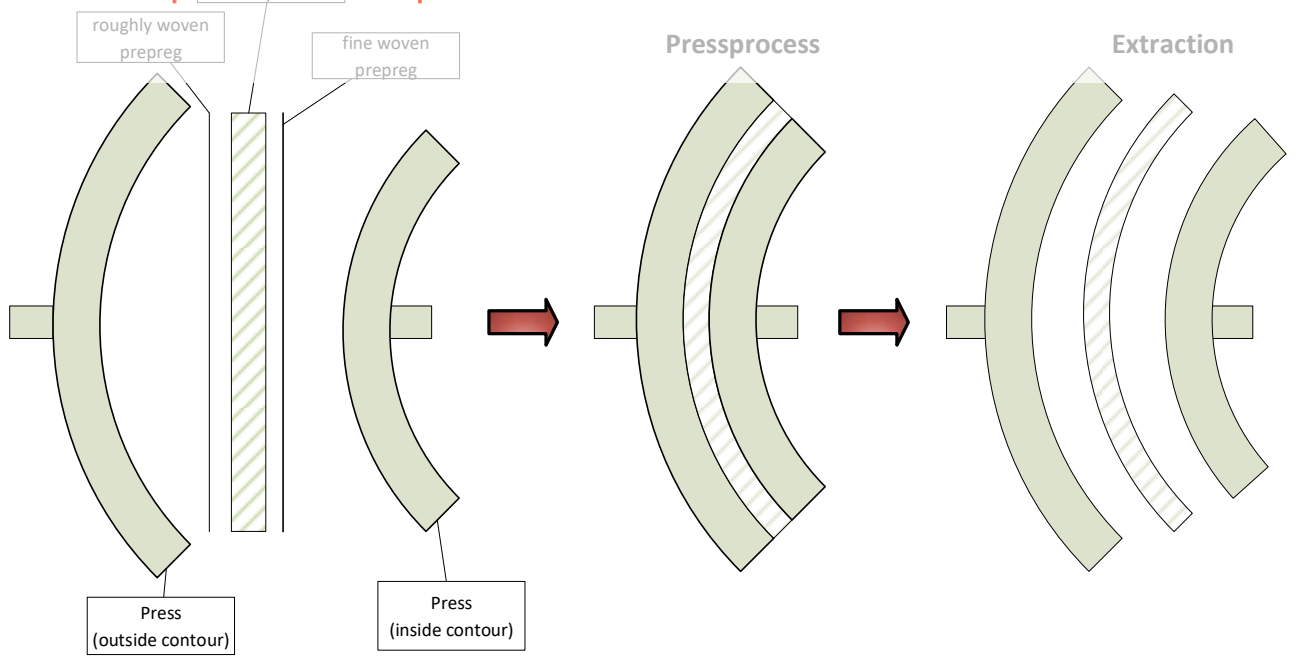

Figure 2: State of the art manufacturing process of aircraft interior lining panels. 


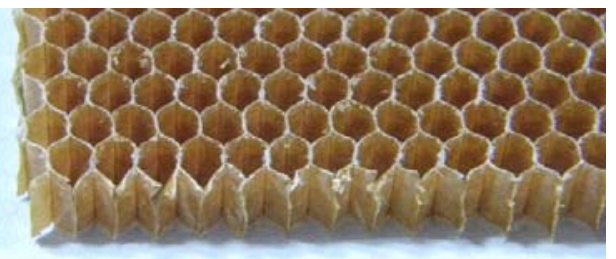

Figure 3: paper honeycomb. $6,5 \mathrm{~mm}$ thickness. Can be used as a sandwich core, healthy or crushed

\section{STRUCTURAL INTEGRATION}

The aim of this project is to produce an active lining that reduces noise inside the cabin. This requires both: sensors and actuators. The vibrations must be transmitted directly from the lining to the sensors. The signals from the sensor array are then transmitted to the control unit. This signal will be analyzed. As response to these vibrations the actuators will be activated in the corresponding bandwith. The forces of the actuators have to be transduced into the structure of the lining. As with any industrial application, installation should be simple. The manufacturing processes should not deviate too much from the current work steps. In addition, the devices must be protected from dirt and moisture.

In order to have a fast repair possibility and to be able to flexibly design the positions of the sensors/actuators, a concept with inserts is pursued at ACASIAS. The inserts consist of plastic holders that form the housing for the needed devices. They also include the electrical connection to the contr pre-pressed slots inside locked. Stamps corres honeycomb sandwich st glass fabric prepregs. I lining during the press process

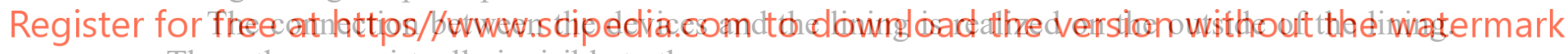
There they are virtually invisible to the passenger.

In ACASIAS the array of sensors and actuators consists of 4 actuators and 6 sensors each. The size of the lining itself is about $1.3 \mathrm{~m} \times 1.7 \mathrm{~m}$. After the production of this test sample at INVENT, the whole device is ready for tests at the DLR.

\section{PRODUCTION OF A LINING WITH INSERTS}

As mentioned, a lining is normally produced in a pressing cycle. For this purpose, the moulds that later form the contour of the lining are heated to the curing temperature of the resin. The materials are placed in the mould and pressed together with the paper honeycomb to form a lining. In this pressing process, the connections and screwing points can also be placed in the mould and then bonded in the same curing process.

Unfortunately, this is not possible within the scope of this research project. Creating new moulds with heating would be beyond the budget. Therefore, we have to validate the curing as well as the shaping for small quantities by alternative processes.

The first tests for gluing and handling such an insert were performed on a press with a straight plate. Different stamp shapes were tested. However, the round shape quickly proved 
to be the best form-fit variant. Reinforcements with finely woven prepreg fabric in this area supports connection to the sandwich structure of the lining for better force transmission (form factor).

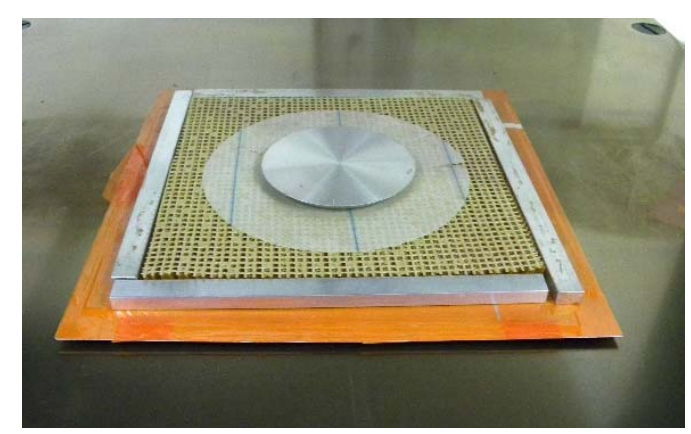

Figure 4: Test sample on a press with preset distance before curing
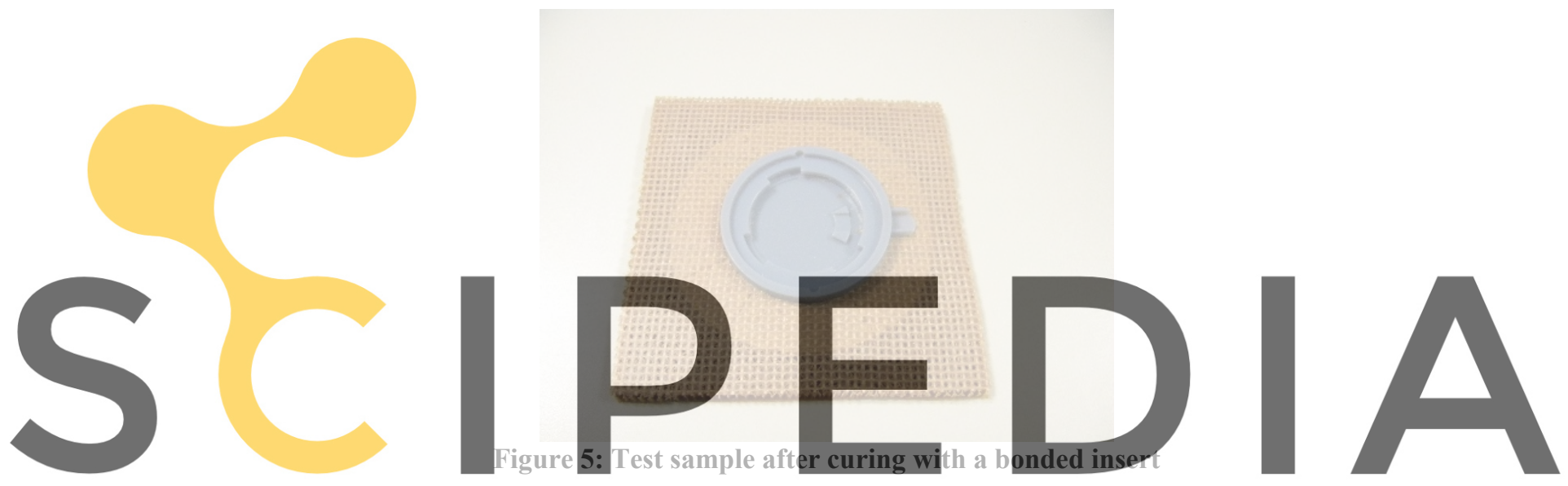

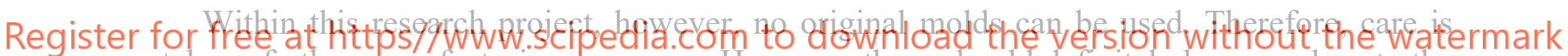 taken of other manufacturing processes. However, these should definitely be very close to the \\ real lining structure. In other words, the product should have a realistic structure.}

In the manufacturing process a mould is built which corresponds to the curvature of a lining. A comparative lining is available. Based on the design data, a positive mold is milled from an epoxy reinforced PU foam. This mould reproduces the inside of the lining (passenger side). The fine glass fiber prepreg is placed on this mold. The paper honeycomb cut to size forms the core of the sandwich. The coarse-meshed fabric is used to form the outer layer of the lining. There, the reinforcements for the inserts are placed at the points determined by DLR and the slots for the crush core are positioned.

Since the original press moulds cannot be used within the context of the project, a suitable hardening process with suitable contact pressures must be found. In the manufacturing process, the mould halves are pressed to distance with 17 bar pressure. Available infrastructure only allows for a manufacturing process in an autoclave with a vacuum setup, like in Figure 6. The pressure inside the autoclave must not be too high, because the paper honeycomb must not be damaged under the pressure. But the pressure must be large enough so that the stamps for the deepening of the inserts can be crushed. 


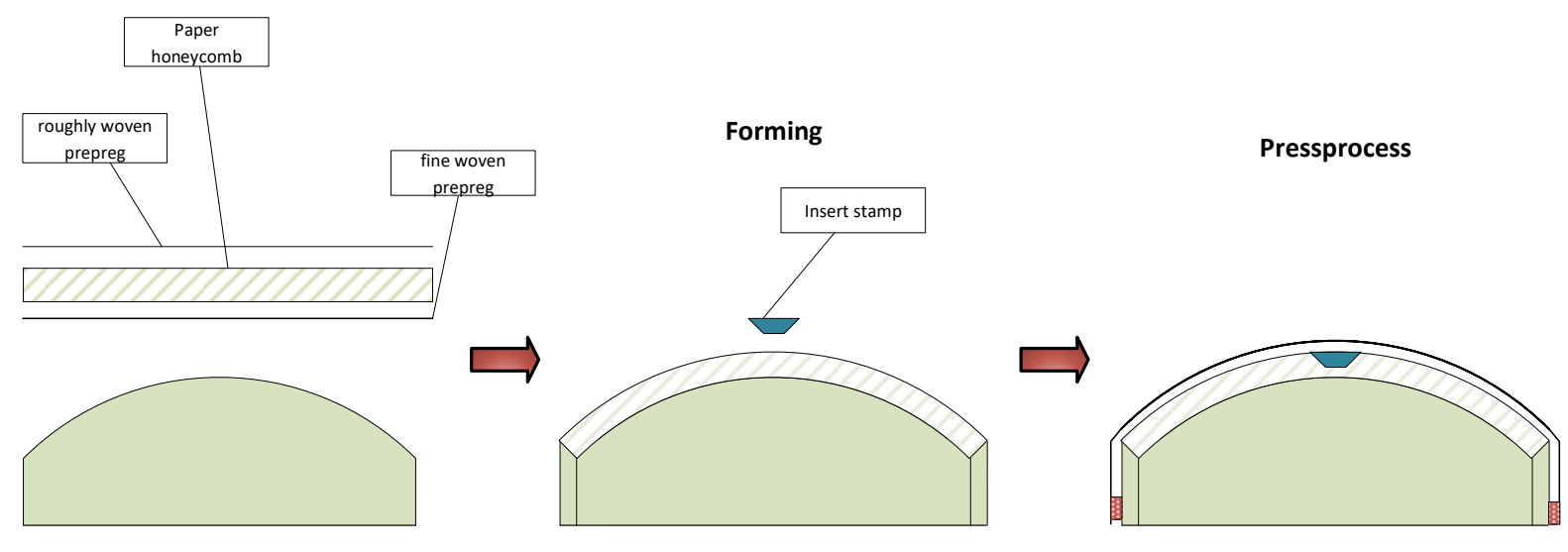

Figure 6: Alternatively curing process and the stamps within the vacuum buildup

First, a material had to be found that was easy to mill, resistant to pressure and that could retain its shape at high temperatures, to be seen at Figure 7 . We achieved the best results with an epoxy reinforced PU foam.
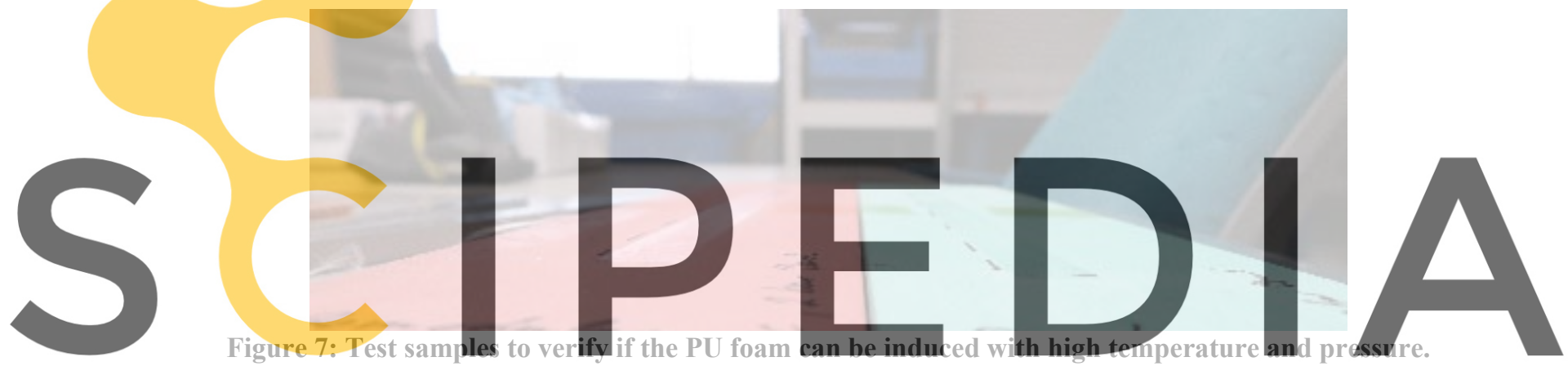

These samples were tested at $160^{\circ} \mathrm{C}$ with $2 \mathrm{bar}$. The material on the left side failed, the other material

Register for free at https//www.scipedia.com to do download the version without the watermark

Another challenge for this alternative hardening process was the setting of the correct pressure or the choice of the correct top layer of the sandwich construction. If a too high pressure in the autoclave is chosen, a compression of the sandwich construction and loss of the part would be a result.

Since the pressure must not be as high as in closed moulds in press production, the areas for the stamps of the inserts must be able to be crushed (pre-damaged). The relatively low pressure compared to the industry standard must still be able to push the stamps into the sandwich construction. Therefore, the paper honeycomb must be pre-damaged. There are two ways to do this:

1. a hole is cut in the intact paper honeycomb where the stamp for production will later also be located. in a separate step, an additional honeycomb piece is pre-damaged (precrushed) in a press. The filling piece corresponding to the hole in the paper honeycomb is then cut out of this pre-damaged piece of paper honeycomb and prepared into the intact lining. Figure 8 .

2. The cut-out paper honeycomb is machined with a milling cutter at the places for the inserts and material is removed at these places. This does not correspond later to the material 
density of a crushed core, but the bond of the paper honeycomb is not so severly damaged and the force distribution within the honeycomb is not interrupted.

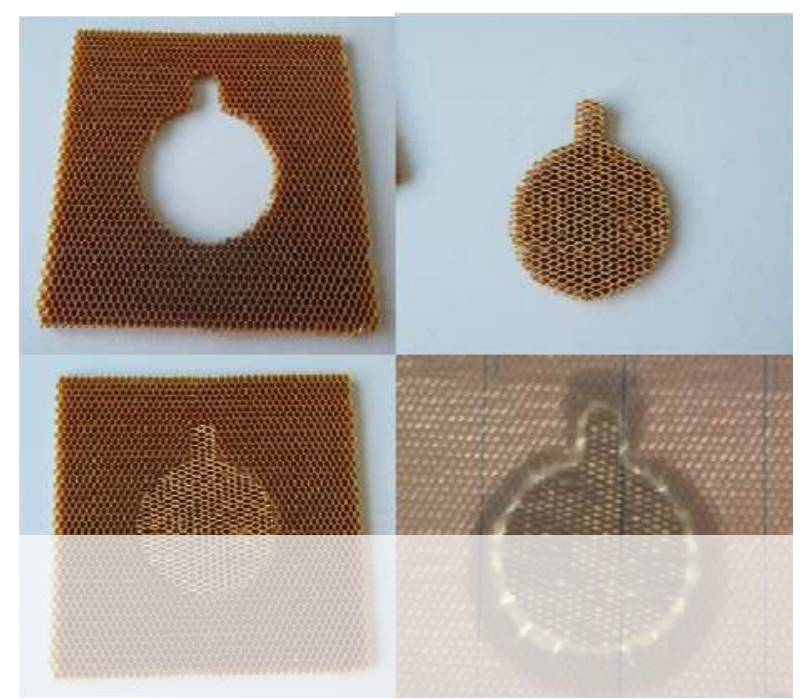

Figure 8: Precutted core, precutted and predamaged inlet for the insert, combined cut outs, pressed and glued sample with interrupted force distribution within the honeycomb

5 REPAIR POSSIBILITES

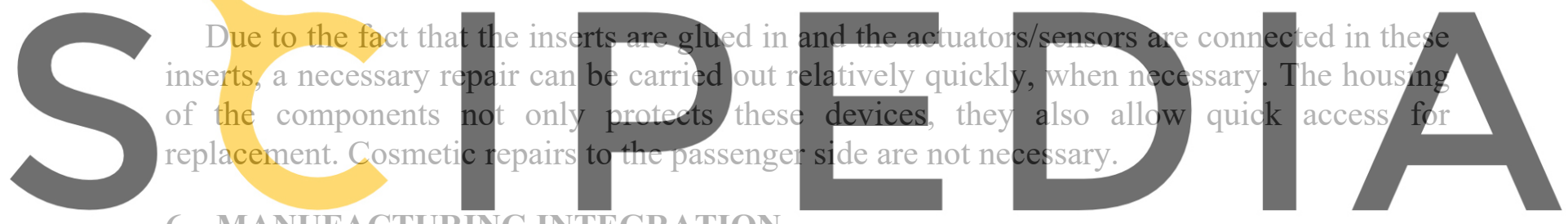

6 MANUFACTURING INTEGRATION

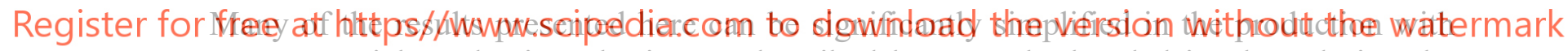
presses. In serial production, the inserts described here can be bonded in place during the pressing process using a backdrop. This would require only minor changes to one of the two forms.

\section{CONCLUSION AND OUTLOOK}

It has been shown that a lining with an array of sensors and actuators can also be produced in small quantities for test purposes. The technical challenges and their solutions have been demonstrated. A manufacturing process as alternative to heated press manufacturing has been developed. With the help of this knowledge, such a lining is produced within the framework of the ACASIAS project and the possibilities of noise reduction are tested in a special sound chamber. 
Kai Gonet, Stefan Steeger, Stephan Algermissen, Victor Lungaho

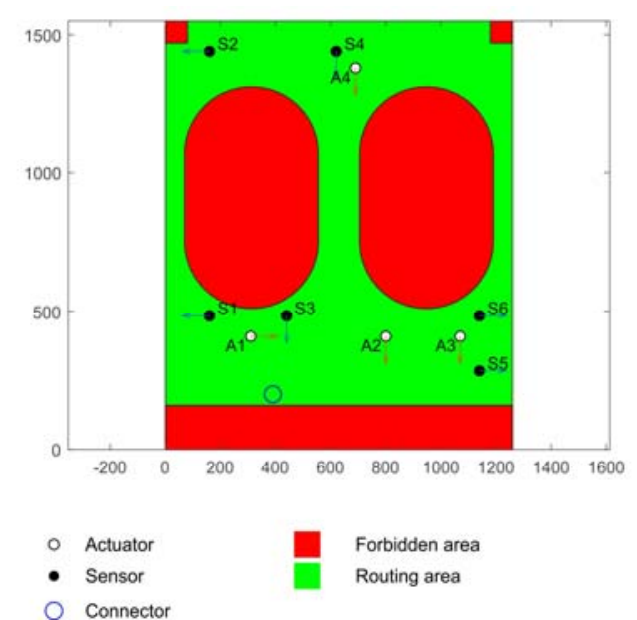

Figure 10: Array of sensors and actuators for the final test sample, view from the pax side

\section{ACKNOWLEDGEMENTS}

All work described in this paper has received funding from the European Union's Horizon 2020 research and innovation programme under grant agreement No 723167, ACASIAS project.

DIEHL, as an industrial partner for this project, supported us with material such as prepregs and paper honeycomb

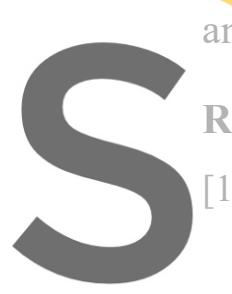

REFERENCES
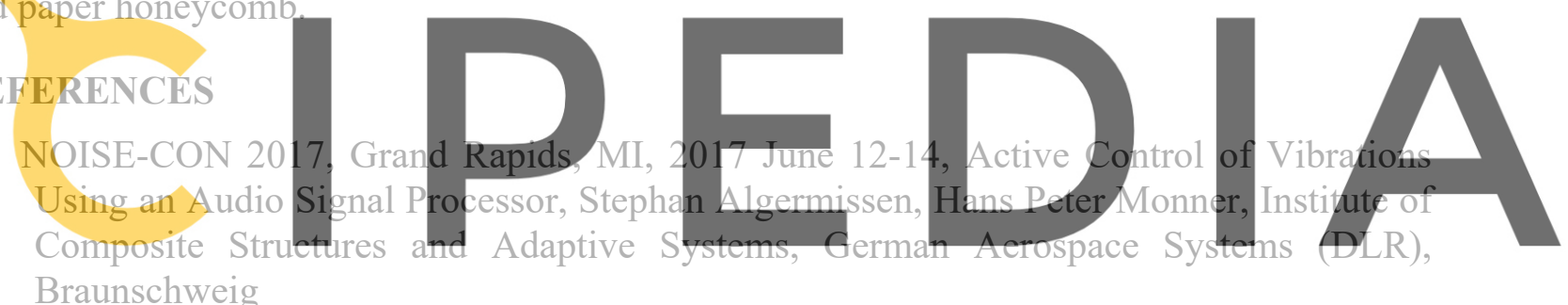

Braunschweig

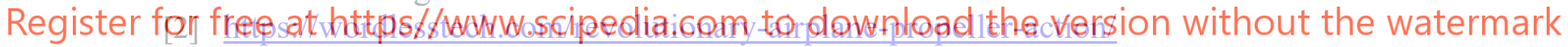

[3] Stephan Algermissen, et al, "Towards a Lining Integrated Active Structural Acoustic

Control System”, paper EMuS 2019, June 2019 